\title{
Detection of soluble HFE associated with soluble transferrin receptor in human serum
}

\author{
KOUHEI OHNISHI ${ }^{1}$, YOSHIHIRO TORIMOTO ${ }^{2}$, KATSUYA IKUTA $^{1}$, HIROKI TANAKA $^{3}$, \\ TAKAAKI HOSOKI ${ }^{1}$, SEIJI TANAKA ${ }^{4}$, AKIEI HAMANO ${ }^{4}$, KAZUYA SATO $^{1}$, \\ MIKIHIRO FUJIYA ${ }^{1}$, KATSUNORI SASAKI ${ }^{3}$ and YUTAKA KOHGO ${ }^{1}$ \\ ${ }^{1}$ Division of Gastroenterology and Hematology/Oncology, Department of Medicine; ${ }^{2}$ Oncology Center; \\ ${ }^{3}$ Department of Gastrointestinal Immunology and Regenerative Medicine, Asahikawa Medical University, \\ 2-1-1-1 Midorigaoka-Higashi, Asahikawa, Hokkaido 078-8510; ${ }^{4}$ Research Laboratory, \\ Nissui Pharmaceutical Co. Ltd., 1075-2 Hokunanmoro, Yuki, Ibaraki 307-0036, Japan
}

Received September 30, 2010; Accepted November 25, 2010

DOI: $10.3892 / \mathrm{ijmm} .2010 .584$

\begin{abstract}
Hereditary hemochromatosis is an autosomal recessive disease, and $80-90 \%$ of patients exhibit Cys282Tyr or His63Asp mutations in the HFE gene. HFE, also known as major histocompatibility complex (MHC) class I-like molecule, binds to transferrin receptor 1 (TfR1) and $\beta 2$-microglobulin at the cell surface, forming a complex. Some MHC class I molecules are known to be soluble, raising the possibility that HFE also has a soluble form. However, it is not known whether soluble HFE (sHFE) is present in human serum, and there has been no report on the possible binding between sHFE and soluble TfR (sTfR), which is the fragment of the extracellular domain of TfR1 released into the blood. In the present study, we purified an sTfR complex from pooled serum collected from healthy volunteers, showing that the main components of the complex are sTfR and transferrin. We also confirmed the existence of sHFE in this complex. This is the first report on the existence of sHFE in human serum.
\end{abstract}

\section{Introduction}

Transferrin receptor 1 (TfR1) is a type II membrane protein, which functions in iron uptake from transferrin by cells via a well-known recycling pathway (1-3). Two identical TfR1 subunits form a homodimer with a disulfide bond near the plasma membrane. In the recycling pathway, a portion of TfR1 is hydrolyzed at the point between Arg100 and Leu101 in the extracellular domain of TfR1. The extracellular domain of

Correspondence to: Dr Katsuya Ikuta, Division of Gastroenterology and Hematology/Oncology, Department of Medicine, Asahikawa Medical University, 2-1-1-1 Midorigaoka-Higashi, Asahikawa, Hokkaido 078-8510, Japan

E-mail: ikuta@asahikawa-med.ac.jp

Key words: transferrin, soluble transferrin receptor, soluble HFE, major histocompatibility complex class I molecule
TfR1 is released from the cells into the blood and is detectable as soluble TfR (sTfR) (4-8). The concentration of sTfR is increased in iron deficiency anemia and autoimmune hemolytic anemia, and is decreased in aplastic anemia and the myelodysplastic syndrome. The concentration of circulating STfR is therefore, a marker of erythropoiesis and iron storage (9-11).

TfR1 binds to HFE, the protein which when mutated is responsible for hereditary hemochromatosis, as well as to $\beta 2$-microglobulin $(\beta 2 \mathrm{~m})$ at the cell surface, forming a complex (12-17). Hereditary hemochromatosis is an autosomal recessive disease, and $80-90 \%$ of patients exhibit Cys282Tyr or His63Asp mutations in the HFE gene. HFE binds to TfR1 in the intracellular endosome bearing the Tf-TfR 1 complex, reducing the binding affinity between TfR 1 and Tf (16,18-20). In addition, HFE has been reported to reduce the rate of TfR1 recycling and of iron uptake (21). HFE has a high similarity to the major histocompatibility complex (MHC) class I proteins. Some MHC class I molecules are known to be soluble (22-29), raising the possibility that $\mathrm{HFE}$ also has a soluble form. Recombinant soluble HFE (sHFE) protein produced by the transfection of the extracellular portion of HFE binds to sTfR, and sHFE can bind to the complex of Tf-TfR1 $(13,30)$. However, it is not known whether sHFE is present in human serum, and there is no report concerned with possible binding between sHFE and sTfR in the circulation. Therefore, we investigated these possibilities.

\section{Materials and methods}

Cell cultures and liver tissues. Human hepatoma-derived HLF cells (Japanese Cancer Resources Bank, Tokyo) were cultured with RPMI-1640 medium supplemented with $10 \%$ fetal bovine serum (FBS), $100 \mathrm{U} / \mathrm{ml}$ penicillin, and $100 \mathrm{mg} / \mathrm{ml}$ streptomycin sulfate at $37^{\circ} \mathrm{C}$ in a $5 \% \mathrm{CO}_{2}$ incubator. Human liver samples were obtained from liver biopsies performed in patients with hepatitis, and used with written permission.

Antibodies. Anti-TfR1 monoclonal antibodies (clone Nos. TR101 and TR112, IgG1, Nissui, Tokyo), anti-Tf monoclonal 
antibody (Biodesign International, ME), and anti-CD5 antibody (B-B8, IgG1, Funakoshi) were used. Anti-HFE antiserum was obtained by vaccination of rabbits with a complex of a recombinant HFE sequence (171-182: RHKIRARQNRAYC) and keyhole limpet hemocyanin. Peroxidase-conjugated antimouse (Rockland, PA) or anti-rabbit (Chemicon, CA) antibodies were used as the secondary antibodies in Western blotting.

Purification of sTfR complex from pooled serum collected from healthy volunteers. Pooled serum $(100 \mathrm{ml})$ collected from healthy volunteers was passed through an anti-TfR1 monoclonal antibody-bound Sepharose-4B column (column volume of $10 \mathrm{ml}$ ), and then washed with phosphate buffered saline (PBS). Elution was performed using ammonium peroxide solution ( $\mathrm{pH}$ 11.0), and the fractions including sTfR were determined by enzyme-linked immunosorbent assay (ELISA) and collected. Next, collected fractions were equilibrated with $0.01 \mathrm{M}$ Tris phosphate ( $\mathrm{pH}$ 8.0), and further purified by passage through a monoQ column (linear gradient of $\mathrm{NaCl}, 0-0.5 \mathrm{M}$ ). Fractions including sTfR were analyzed by ELISA, for use in the present study. Protein concentrations were determined by the Lowry method (Bio-Rad, CA).

ELISA. Ninety-six-well plates were coated with $100 \mu \mathrm{g} / \mathrm{ml}$ of the anti-TfR1 antibody (TR112) for $3 \mathrm{~h}$ at room temperature, and then blocking was performed using PBS with $1 \%$ bovine serum albumin (BSA). Anti-TfR1 antibody clone TR101 was used for the detection. Color assays were performed using $4.5 \mathrm{mM}$ disodium phenylphosphate and $2 \mathrm{mM} 4$-aminoantipyrine as the substrate. Absorbance was measured at $490 \mathrm{~nm}$.

SDS-PAGE and silver staining. Cultured cells were harvested with a cell scraper, washed with PBS twice, and then incubated with lysis buffer ( $50 \mathrm{mM}$ Tris-HCl, $\mathrm{pH} 7.5,150 \mathrm{mM} \mathrm{NaCl}$, $1 \mathrm{mM}$ phenylmethylsulfonyl fluoride, $1.0 \%$ Nonidet P-40) for $30 \mathrm{~min}$ at $4^{\circ} \mathrm{C}$. Human liver tissues were homogenized with lysis buffer. Both samples were centrifuged at $14,000 \mathrm{rpm}$ for $10 \mathrm{~min}$ at $4^{\circ} \mathrm{C}$ and then the supernatant was collected. Collected samples were mixed with Laemmli sample buffer (Bio-Rad) for $5 \mathrm{~min}$ at $96^{\circ} \mathrm{C}$ and used for sodium dodecyl sulfate-polyacrylamide gel electrophoresis (SDS-PAGE) with 8 or $10 \%$ SDS-polyacrylamide gels. A silver stain reagent kit (Daiichi-Kagaku-Yakuhin) was used for silver staining.

Immunoprecipitation. Lysates obtained from cultured cells, human liver tissues, and purified sTfR fractions were incubated with protein G-Sepharose (Pharmacia Biotech, Uppsala, Sweden) and centrifuged. Supernatants were collected, and primary antibody was added and incubated for $8 \mathrm{~h}$ at $4^{\circ} \mathrm{C}$. Washing was performed with lysis buffer twice, then Laemmli sample buffer was added, followed by incubation for $5 \mathrm{~min}$ at $96^{\circ} \mathrm{C}$. Finally, the samples were applied for SDS-PAGE.

Western blotting. After SDS-PAGE, proteins were transferred to nitrocellulose membranes. Nitrocellulose membranes were treated with blocking buffer (5\% skim milk dissolved in 0.05\% Tween-PBS) at $4^{\circ} \mathrm{C}$ overnight, washed with $0.05 \%$ Tween-PBS, and then incubated with peroxidase-conjugated secondary antibody for $1 \mathrm{~h}$ at room temperature. After washing with $0.05 \%$ Tween-PBS, the ECL chemiluminescence system (Amersham,
Buckinghamshire, UK) was used for detection. To determine the specificity of the produced anti-HFE antibody, Western blotting was performed as above using the anti-HFE antibody mixed with peptide $(8 \mu \mathrm{g} / \mathrm{ml})$ which was used as antigen for producing the anti-HFE antibody.

Transfection of HLF cells with the HFE gene. Total RNA was purified from human hepatoma-derived Chang cells using RNAgents total RNA isolation system (Promega). Complementary DNA was synthesized by reverse transcription with M-MLV Reverse Transcriptase (Promega) using an oligo dT primer (Invitrogen, CA). Nested polymerase chain reaction (PCR) was then performed using Taq DNA polymerase (Takara) and 3 primers (first sense: 5'-CTGAGCCTAGGCA ATAGCTG-3', second sense: 5'-TAGGGTGACTTCTGGAG CCA-3', first and second antisense: 5'-TCACGTTAGCTAAG ACGTA-3'). The entire coding region of the HFE gene without a stop codon (position -86 to 1043) was amplified by PCR . Forty thermal cycles of $94^{\circ} \mathrm{C}$ for $4 \mathrm{~min}, 55^{\circ} \mathrm{C}$ for $1 \mathrm{~min}$, and $72^{\circ} \mathrm{C}$ for 2 min were performed. The PCR product was ligated in pT7 blue vector (Novagen, Madison, WI), and its sequences confirmed using the ABI PRISM ${ }^{\mathrm{TM}} 310$ Genetic Analyzer (Applied Biosystems). Subcloning of the HFE gene to the mammalian expression $\mathrm{pRc} / \mathrm{CMV}$ vector (Invitrogen) was then performed. Transfection of HLF cells with the pRc/CMV vector bearing the HFE gene was carried out by lipofection using the GenePorter kit (Gene Therapy Systems, CA). Cells were harvested $48 \mathrm{~h}$ after transfection.

Labeling of the sTfR fraction with ${ }^{125}$ I. Purified sTfR fraction (20 $\mu 1,50 \mu \mathrm{g} / \mathrm{ml}$ ), IODO-Beads (Iodinating reagent, Pierce), $40 \mu \mathrm{Ci}$ of ${ }^{125} \mathrm{I}$ (Amersham), and $500 \mu \mathrm{l}$ of $100 \mathrm{mM}$ Tris-HCl were mixed and incubated for $15 \mathrm{~min}$ at room temperature. The mixture was passed through a PD-10 column (Bio-Rad), and collected fractions were assayed with a gamma counter. Fractions labeled with ${ }^{125}$ I were then collected and used in the experiments.

\section{Results}

Purification of the sTfR complex from pooled sera of healthy volunteers. Due to the fact that the serum concentration of HFE was expected to be low, and a method for purifying only HFE was not available, we tried to purify sTfR that might include soluble HFE. Pooled serum collected from healthy volunteers was isolated by affinity chromatography using an anti-TfR1 monoclonal antibody-bound Sepharose-4B column. The sTfR complex was further purified by ion-exchange chromatography utilizing a monoQ column and a linear gradient of $\mathrm{NaCl}$. The concentrations of eluted proteins as a function of $\mathrm{NaCl}$ concentration, as well as the absorbancies measured by ELISA for quantifying the concentration of sTfR in each fraction are shown in Fig. 1A. The concentrations of sTfR indicated by the absorbancies at OD $490 \mathrm{~nm}$ were relatively high in the fractions eluted in $0.2-0.3 \mathrm{M} \mathrm{NaCl}$. These fractions were collected, and used for further experiments.

Characteristics of the purified sTfR fractions. To determine the characteristics of the purified sTfR fractions, $10 \mathrm{mg}$ of purified protein were applied for SDS-PAGE electrophoresis 
A

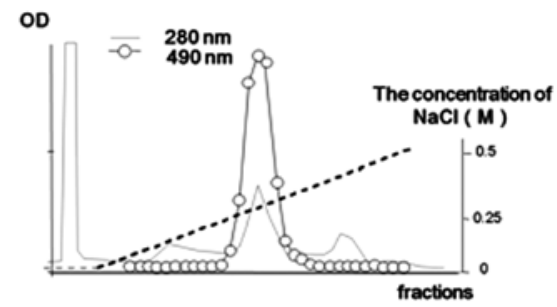

B

C

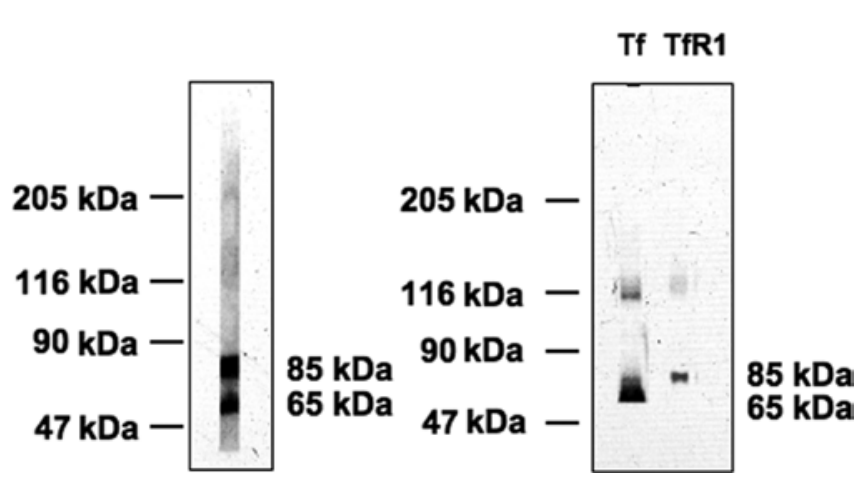

Figure 1. (A) Purification of sTfR by ion-exchange chromatography. Fractions including sTfR were concentrated from pooled serum collected from healthy volunteers using an anti-TfR1 antibody-bound Sepharose 4B column, and then passed through an ion-exchange monoQ column. Finally, fractions were eluted using the gradient concentrations of $\mathrm{NaCl}$. The dotted line indicates the concentration of $\mathrm{NaCl}$; the solid line indicates the concentrations of eluted proteins measured by the absorbancies at $280 \mathrm{~nm}$; and the open circles indicate the concentration of sTfR measured by the absorbancies at $490 \mathrm{~nm}$ with the ELISA system. (B) Silver staining for the purified fraction of sTfR after SDS-PAGE. Two bands corresponding to $85 \mathrm{kDa}$ and $65 \mathrm{kDa}$ proteins were observed. (C) Western blot analysis for the purified fraction of sTfR after SDS-PAGE using an anti-Tf (Tf) and an anti-TfR1 antibody (TfR1). Two bands corresponding to $85 \mathrm{kDa}$ and $65 \mathrm{kDa}$ proteins were observed, indicating these proteins were sTfR and Tf, respectively.

and silver staining. Although a broad non-specific band could be seen at the region of high molecular weight, silver staining showed clear bands with apparent molecular weights of 85 and $65 \mathrm{kDa}$ (Fig. 1B). To identify these proteins, Western blotting was performed. The band at $85 \mathrm{kDa}$ reacted with the anti-TfR 1 antibody and the band at $65 \mathrm{kDa}$ reacted with the anti-Tf antibody (Fig. 1C) confirming that the principal components of the sTfR fraction were sTfR and Tf. This result verifies a previous report concerning the main components of the sTfR fraction purified from pooled sera of healthy volunteers (31).

Determination of the specificity of the anti-HFE antibody against HFE. The specificity of the anti-HFE antibody made by immunization of a rabbit with HFE was determined. Lysates were prepared from liver tissues expressing HFE, human hepatoma-derived HLF cells that did not express any HFE, and the transiently transfected HLF cells (HLF-Tr) with HFE expression vector. SDS-PAGE was performed after immunoprecipitation with the anti-TfR1 antibody, and then Western blotting was performed using the anti-HFE antibody. The band at $48 \mathrm{kDa}$ in the liver tissue was considered to be HFE, but
A

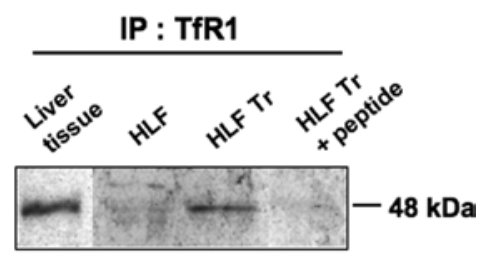

B

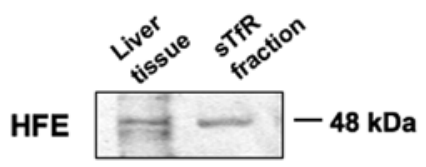

C

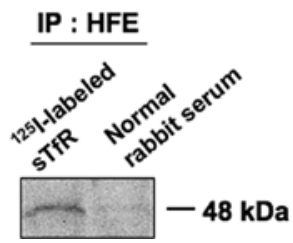

Figure 2. (A) Determination of the specificity of the anti-HFE antiserum. To determine the specificity of the anti-HFE antiserum produced by vaccination of a rabblit with the HFE peptide, lysates prepared as indicated were applied for immunoprecipitation by an anti-TfR 1 antibody followed by Western blotting with the anti-HFE antiserum. Lysates were prepared from liver tissues, human hepatoma-derived HLF cells without the expression of HFE, transfected HLF cells with HFE expression vector (HLF-Tr), HLF-Tr lysate blocked by the peptide used as an antigen. (B) Western blotting for the purified sTfR fraction using the anti-HFE antiserum. The purified sTfR fraction was taken for SDS-PAGE followed by Western blotting using the anti-HFE antiserum. Bands corresponding to $48 \mathrm{kDa}$ were observed in both samples. Lysates were prepared from liver tissues and the purified sTfR fraction. (C) Immmunoprecipitation from ${ }^{125}$ I-labeled purified sTfR fraction using the anti-HFE antiserum. The purified sTfR fraction was labeled with ${ }^{125} \mathrm{I}$ and then subjected to immunoprecipitation using an anti-HFE antibody followed by SDS-PAGE. The $48 \mathrm{kDa}$ protein was immunoprecipitated with the anti-HFE antibody. Normal rabbit serum was used as the negative control.

no band was observed in HLF cells (Fig. 2A). HLF-Tr cells showed the band at the molecular weight of $48 \mathrm{kDa}$ as the same as that in the liver tissue (Fig. 2A). The reactivity of the antiHFE antibody was inhibited by the peptide which was used for vaccination of the rabbit, indicating that the produced antibody specifically recognized and reacted with HFE (Fig. 2A).

Detection of soluble HFE in the purified sTfR fractions. To determine if HFE was present in the purified sTfR fractions, lysates from liver tissues and purified protein were subjected to SDS-PAGE followed by Western blotting using the anti-HFE antibody. The band was observed in the purified sTfR fraction at $48 \mathrm{kDa}$ similarly to the plasma membrane-bound HFE from liver tissues (Fig. 2B). The purified protein was then labeled with ${ }^{125} \mathrm{I}$ and immunoprecipitated with the anti-HFE antibody. The band observed at $48 \mathrm{kDa}$ in the ${ }^{125} \mathrm{I}$-labeled sTfR fraction was separated by SDS-PAGE after immunoprecipitation with the anti-HFE antibody (Fig. 2C). In contrast, no band was observed in the negative control when normal rabbit serum was used for immunoprecipitation. These results indicate that the size of sHFE was almost the same as that of the membranebound HFE. However, the concentrations of SHFE in healthy donors were considered to be very low compared to STfR and Tf since no band was observed at $48 \mathrm{kDa}$ with silver staining (Fig. 1B). 
A

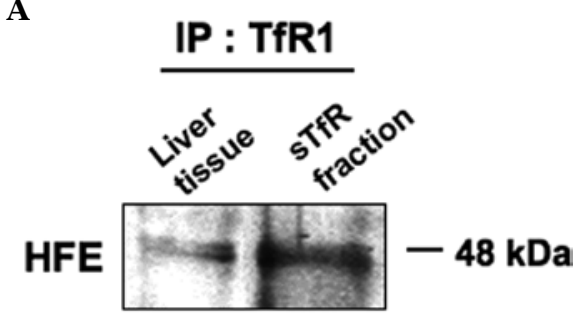

B

\section{IP : HFE}
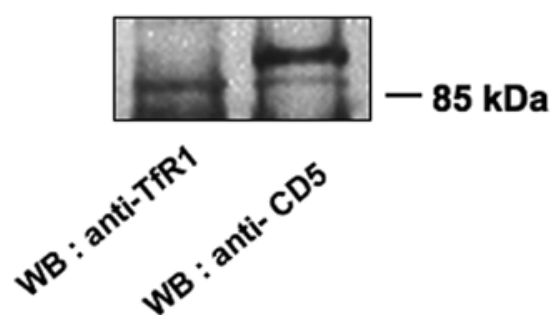

Figure 3. (A) Determination of sHFE bound with sTfR in the purified sTfR fraction by an anti-TfR1 antibody. Lysates prepared from liver tissues and the sTfR fraction were immunoprecipitated using an anti-TfR1 antibody. After immunoprecipitation, SDS-PAGE was performed, followed by Western blotting using the anti-HFE antibody. Bands corresponding to $48 \mathrm{kDa}$ were observed in both lanes, indicating that both were precipitable with TfR1. (B) Detemination of soluble TfR bound with soluble HFE in the purified soluble TfR fraction by an anti-HFE antibody. Lysates prepared from the sTfR fraction were immunoprecipitated using an anti-HFE antibody. After immunoprecipitation, SDS-PAGE was performed, followed by Western blotting using an anti-TfR1 antibody or an anti-CD5 antibody (negative control) The band corresponding to the $85 \mathrm{kDa}$ protein was observed in the left lane.

Determination of the complex formed between sTfR and sHFE. To determine whether sHFE forms a complex with TfR1, immunoprecipitation and Western blotting using an anti-TfR antibody and the anti-HFE antibody were performed. Western blotting and SDS-PAGE showed clear $48 \mathrm{kDa}$ bands in the lysate prepared from liver tissues and the sTfR fraction (Fig. 3A). In contrast, Western blotting using the anti-TfR1 antibody after immunoprecipitation with the anti-HFE antibody and SDS-PAGE showed clear bands at $85 \mathrm{kDa}$ in the sTfR fraction (Fig. 3B). No band at $85 \mathrm{kDa}$ using the anti-CD5 antibody as a negative control was seen. We therefore, conclude that HFE on the cell surface is released into the serum as a soluble form with almost same molecular weight as the membrane-bound HFE, and binds to sTfR to form a complex.

\section{Discussion}

In the present study, sTfR fractions were purified from the serum of healthy volunteers using an affinity column with an anti-TfR1 antibody and a monoQ column. It was confirmed that the main contents of the purified fractions were sTfR and Tf. Soluble HFE was also found, although its amount was very small. This is the first report indicating the presence of HFE as a soluble form bound to sTfR in serum. There are reports that HFE forms lacking the $\alpha$ domain or a portion of it, apparently products of alternative splicing that alters the sequence with which HFE binds to TfR1 (32-34), resulting in SHFE that cannot form a complex with sTfR, may also circulate. Further investigation is warranted.
HFE belongs to MHC class Ib, and has constructive homology with MHC class Ia in which HLA-A, -B, and -C belong. They have the $\alpha$ chain as an extracellular domain $(\alpha 1, \alpha 2, \alpha 3$ domains), a transmembranous domain, and an intracellular domain and therefore, are transmembrane proteins. The existence of a soluble form has been reported in MHC class Ia, and it was also reported that the serum concentration and the molecular conformation are related to the disease activity and to complications in liver or kidney transplantations $(22,26)$, to systemic lupus erythematosus, and to rheumatoid arthritis $(25,28,29)$. MHC class Ib has also been reported to have a soluble form $(35,36)$, and the serum concentration of HLA-G which belongs to this MHC class was useful for the diagnosis of placental abruption (37) and lymphoproliferative diseases (38). The clinical significance of the soluble HFE should be clarified by further studies.

Three conformational variants of the soluble forms of MHC class Ia and Ib have been identified $(27-29,35,36)$. The first one has been digested just external to the cell membrane by metalloproteinase, resulting in a smaller molecular weight compared to the membrane-bound protein. The second type is produced by alternative splicing that leads to loss of the transmembrane portion of the protein. The third is released into the serum following shedding or destruction of cells and exhibits a molecular weight almost the same as that of the intact membrane-bound protein. The soluble HFE observed in the present study has a molecular weight of $48 \mathrm{kDa}$ identical to that of membrane-bound HFE, implying that the soluble HFE possesses both transmembrane and intracellular portions and is released into the circulation by cell shedding or destruction.

We confirm that recombinant sHFE protein produced by CHO cells $(13,30), \mathrm{Tf}$, and recombinant sTfR form a complex, with a stoichiometry resembling that observed at the cell surface where recombinant sTfR forms a dimer. It has also been reported that a Tf molecule and an sHFE molecule could bind to the dimer of STfR, and that two sHFE molecules could bind to the dimer of sTfR when the concentration of SHFE is increased. However, the stoichiometry may change because sTfR in the serum may be a monomeric fragment from digestion at the region of disulfide bond formation. Complexes formed with one molecule of sTfR and one molecule of Tf, and with two molecules of sTfR and two molecules of $\mathrm{Tf}$ have been described (31), and a complex with two molecules of sTfR and one molecule of Tf has been found in decreased iron loads (39). We could find no data on whether a complex of sHFE and Tf exists. A complex of monomeric sTfR and sHFE and Tf is not expected because the binding site of sTfR and Tf partly overlaps with the binding site of sTfR and SHFE (30). However, the fact that two molecules of sTfR and two molecules of $\mathrm{Tf}$ could form a complex suggests the existence of a complex of two molecules of STfR with one molecule of $\mathrm{Tf}$ and one molecule of sHFE.

We have shown that sHFE binds to sTfR. Whether the concentration of serum sHFE has some direct or indirect effect on iron absorption and iron sequestering of the cells remains unclear. Concentrations of sHFE might fluctuate with the volume of HFE-expressing cells or the catabolim of a growing cell. Further investigation is required to determine if there is an effect on iron metabolism, and a possible clinical relevance of the findings. 
In conclusion, we purified an sTfR complex from pooled serum collected from healthy volunteers, showing that the main components of the complex were sTfR and Tf. We also confirmed the existence of sHFE in that complex. We believe this is the first report on the existence of sHFE in normal healthy people. HFE expressed on the cell surface was found to be released from the cells to the serum in a soluble form which complexes to sTfR. The clinical significance of our findings is not yet clear.

\section{Acknowledgements}

We thank Dr Philip Aisen for reviewing this manuscript.

\section{References}

1. Schneider C, Sutherland R, Newman R and Greaves M: Structural features of the cell surface receptor for transferrin that is recognized by the monoclonal antibody OKT9. J Biol Chem 257: 8516-8522, 1982

2. Schneider C, Owen MJ, Banville D and Williams JG: Primary structure of human transferrin receptor deduced from the mRNA sequence. Nature 311: 675-678, 1984.

3. Aisen P: Transferrin receptor 1. Int J Biochem Cell Biol 36: 2137-2143, 2004

4. Kohgo Y, Nishisato T, Kondo H, Tsushima N, Niitsu Y and Urushizaki I: Circulating transferrin receptor in human serum. Br J Haematol 64: 277-281, 1986.

5. Kohgo Y: Structure of transferrin and transferrin receptor. Nippon Ketsueki Gakkai Zasshi 49: 1627-1634, 1986.

6. Shih YJ, Baynes RD, Hudson BG, Flowers CH, Skikne BS and Cook JD: Serum transferrin receptor is a truncated form of tissue receptor. J Biol Chem 265: 19077-19081, 1990.

7. Cook JD, Skikne BS and Baynes RD: Serum transferrin receptor. Annu Rev Med 44: 63-74, 1993.

8. Baynes RD, Shih YJ and Cook JD: Mechanism of production of the serum transferrin receptor. Adv Exp Med Biol 356: 61-68, 1994.

9. Kohgo Y, Niitsu Y, Kondo H, Kato J, Tsushima N, Sasaki K, Hirayama M, Numata T, Nishisato T and Urushizaki I: Serum transferrin receptor as a new index of erythropoiesis. Blood 70: 1955-1958, 1987.

10. Feelders RA, Kuiper-Kramer EP and van Eijk HG: Structure, function and clinical significance of transferrin receptors. Clin Chem Lab Med 37: 1-10, 1999.

11. Kohgo Y, Torimoto Y and Kato J: Transferrin receptor in tissue and serum: updated clinical significance of soluble receptor. Int J Hematol 76: 213-218, 2002.

12. Feder JN, Gnirke A, Thomas W, et al: A novel MHC class I-like gene is mutated in patients with hereditary haemochromatosis. Nat Genet 13: 399-408, 1996.

13. Lebrón JA, Bennett MJ, Vaughn DE, Chirino AJ, Snow PM, Mintier GA, Feder JN and Bjorkman PJ: Crystal structure of the hemochromatosis protein HFE and characterization of its interaction with transferrin receptor. Cell 93: 111-123, 1998.

14. Bennett MJ, Lebrón JA and Bjorkman PJ: Crystal structure of the hereditary haemochromatosis protein HFE complexed with transferrin receptor. Nature 403: 46-53, 2000.

15. Parkkila S, Waheed A, Britton RS, et al: Association of the transferrin receptor in human placenta with HFE, the protein defective in hereditary hemochromatosis. Proc Natl Acad Sci USA 94: 13198-13202, 1997.

16. Feder JN, Penny DM, Irrinki A, et al: The hemochromatosis gene product complexes with the transferrin receptor and lowers its affinity for ligand binding. Proc Natl Acad Sci USA 95: 1472-1477, 1998.

17. Waheed A, Parkkila S, Saarnio J, et al: Association of HFE protein with transferrin receptor in crypt enterocytes of human duodenum. Proc Natl Acad Sci USA 96: 1579-1584, 1999.
18. Feder JN, Tsuchihashi Z, Irrinki A, et al: The hemochromatosis founder mutation in HLA-H disrupts beta2-microglobulin interaction and cell surface expression. J Biol Chem 272: 14025$14028,1997$.

19. Gross CN, Irrinki A, Feder JN and Enns CA: Co-trafficking of HFE, a non-classical major histocompatibility complex class I protein, with the transferrin receptor implies a role in intracellular iron regulation. J Biol Chem 273: 22068-22074, 1998.

20. Lebrón JA, West AP Jr. and Bjorkman PJ: The hemochromatosis protein HFE competes with transferrin for binding to the transferrin receptor. J Mol Biol 294: 239-245, 1999.

21. Ikuta K, Fujimoto Y, Suzuki Y, et al: Overexpression of hemochromatosis protein, HFE, alters transferrin recycling process in human hepatoma cells. Biochim Biophys Acta 1496: 221-231, 2000.

22. Zavazava N, Leimenstoll G and Müller-Ruchholtz W: Measurement of soluble MHC class I molecules in renal graft patients: a noninvasive allograft monitor. J Clin Lab Anal 4: 426-429, 1990

23. Haga JA, She JX and Kao KJ: Biochemical characterization of 39-kDa class I histocompatibility antigen in plasma. A secretable membrane protein derived from transmembrane domain deletion. J Biol Chem 266: 3695-3701, 1991.

24. Zavazava N, Wobst B, Ferstl R and Müller-Ruchholtz W: Soluble MHC class I molecules in human body fluids. J Clin Lab Anal 8: 432-436, 1994.

25. Bresciani A, Pirozzi G, Spera M, et al: Increased level of serum HLA class I antigens in patients with systemic lupus in patients with systemic lupus erythematosus. Correlation with disease activity. Tissue Antigens 52: 44-50, 1998.

26. Hagihara M, Munkhbat B, Kanai N, et al: Serum soluble human leucocyte antigen class $\mathrm{I}$ in paediatric liver transplantation with live, related donors. Transpl Immunol 5: 219-224, 1997.

27. Haynes LD, Bushkin Y, Love RB and Burlingham WJ: Interferon-gamma drives the metalloproteinase-dependent cleavage of HLA class I soluble forms from primary human bronchial epithelial cells. Hum Immunol 63: 893-901, 2002.

28. Adamashvili I, Pressly T, Gebel H, et al: Soluble HLA in saliva of patients with autoimmune rheumatic diseases. Rheumatol Int 22: 71-76, 2002.

29. Adamashvili I, Wolf R, Aultman D, et al: Soluble HLA-I (s-HLA-I) synthesis in systemic lupus erythematosus. Rheumatol Int 23: 294-300, 2003.

30. West AP Jr, Giannetti AM, Herr AB, et al: Mutational analysis of the transferrin receptor reveals overlapping HFE and transferrin binding sites. J Mol Biol 313: 385-397, 2001.

31. Hikawa A, Nomata Y, Suzuki T, Ozasa H and Yamada O: Soluble transferrin receptor-transferrin complex in serum: measurement by latex agglutination nephelometric immunoassay. Clin Chim Acta 254: 159-172, 1996.

32. Rhodes DA and Trowsdale J: Alternate splice variants of the hemochromatosis gene Hfe. Immunogenetics 49: 357-359, 1999.

33. Thénie A, Orhant M, Gicquel I, Fergelot P, Le Gall JY, David V and Mosser J: The HFE gene undergoes alternate splicing processes. Blood Cells Mol Dis 26: 155-162, 2000.

34. Sánchez M, Bruguera M, Rodés J and Oliva R: Complete characterization of the 3 region of the human and mouse hereditary hemochromatosis HFE gene and detection of novel splicing forms. Blood Cells Mol Dis 27: 35-43, 2001.

35. Rebmann V, Pfeiffer K, Pässler M, Ferrone S, Maier S, Weiss E and Grosse-Wilde H: Detection of soluble HLA-G molecules in plasma and amniotic fluid. Tissue Antigens 53: 14-22, 1999.

36. Dong Y, Lieskovska J, Kedrin D, Porcelli S, Mandelboim O and Bushkin Y: Soluble nonclassical HLA generated by the metalloproteinase pathway. Hum Immunol 64: 802-810, 2003.

37. Steinborn A, Rebmann V, Scharf A, Sohn C and Grosse-Wilde H Placental abruption is associated with decreased maternal plasma levels of soluble HLA-G. J Clin Immunol 23: 307-314, 2003.

38. Sebti Y, Le Friec G, Pangault C, et al: Soluble HLA-G molecules are increased in lymphoproliferative disorders. Hum Immunol 64: 1093-1101, 2003

39. Kato J, Kobune M, Kohgo Y, et al: Ratio of transferrin (Tf) to Tf-receptor complex in circulation differs depending on Tf iron saturation. Clin Chem 48: 181-183, 2002. 